\section{Concert 7}

Tuesday, Aug 7, 2018, 8:00 p.m.

Grand Hall, Daegu Concert House

Reviewed by Martin Ritter

Concert 7 took place in the Grand Hall in Daegu and featured several works with high technical demands. Many of the concerts ran smoothly and without technical difficulties, this particular concert experienced several such difficulties that slowed an already lengthy program. Out of the scheduled ten pieces, four had (multiple) false starts or other technical issues. This considerably lengthened the already very long runtime of the concert. Another common problem at conferences such as these, especially when there are simply so many pieces and the aforementioned technical problems, is that concerts often run so late that audience members must leave before the final piece if they wish to see the late night concert (or miss the beginning of the late night concert).

For this review, I will again focus solely on the sound alone, reserving the reading of the program notes for after my initial reaction, as outlined more in detail in my review of concert 1 .

The opening piece, As hovering ashes in a quarter moon, for cello and electronics by Chen-Hui Jen, was the first, but by no means the last to fall victim to technical difficulties and had to be restarted only a couple of measures in. Afterwards, the piece ran without further interruptions or obvious issues.

The cello line was composed with a very traditional, and highly idiomatic melody, which while underscoring some of the intended ritual had the unfortunate effect of sonic and harmonic stasis. The electronic treatment of the instrument was very restrained using techniques such as delay, ring modulation, and frequency shift, which suited the melodic writing and the overall concept of memory, hovering, and residue. Pre-recorded string instruments other than the cello were used later in the piece. These sounds seemed confusing and out of context, considering the notion of hovering ashes and a Buddhist funeral. A more restrained set or samples to complement the ritual might have been more appropriate. This would have elevated the restraint shown in the melodic writing as well as the restrictions used in the live electronic portions.

Smart-alienation, for small flexible ensemble, electronics and video by Igor Silva, the second piece, had two false starts 
with lengthy periods of waiting in between each, before successfully running on the third. On the first attempt, the ensemble could not hear the click track and on the second the click track was erroneously routed to all the speakers for everyone to hear.

The EA components as well as the video used glitch very effectively, rapidly cutting between noise, glitch, and pure tones/images. Highly rhythmic and energetic, the tight coupling between these two technical spheres (audio and video) made for an interesting and engaging performance. The instrumental writing (flute, clarinet, cello, bass, percussion), while technically well executed by the composer and synched effectively to the other material, was underwhelming. For the majority of the time, the ensemble appeared to be using a popular film/game scoring technique called mickey-mousing. They did not offer new points of view nor develop the already skillfully assembled electronic materials. The piece might have had a stronger impact and would have been more affective if it was trimmed down to the electronic and video parts, foregoing the added complexities of the live, click tracked instrumental performance.

\section{Tourbilloner, danser une danse sonore...,}

for tárogató and electronics by Cort Lippe was the third piece, and also had to be restarted only several measures in since apparently no audio signal was received from the performer. From a purely technical perspective this piece certainly was one of the more complex ones of the evening, as well as containing the most virtuosic live performance. What the performer was able to achieve technically on the tárogató (a single reed, conical-bore instrument commonly used in Hungary and Romania) was nothing short of stunning. The DSP processes accompanying, enhancing, changing the live performance were flawless, of high quality and expertly executed by the composer live in concert. The program notes stated, "this piece is a trio of sorts." However, the system seemed to react to the input of the performer and at no time was it obvious that either the performer had to react or adapt to the system nor how the composer, the theoretical third member fit into this description. Nevertheless, this does not in any way diminish the virtuosic display we witnessed on stage and on the computer.

Moel Y Gaer, Bodfari, for fixed media (audio) by Christopher Lock had a 
fascinating concept: take excavation site diagrams, convert them to graphical notation in the IanniX software, and assign triggers/nodes derived from sites of interest from the actual dig. This score is then played back in IanniX and interpreted in Max where these triggers are mapped to different sounds and functions. Unfortunately, the IanniX score was not shown during the performance. This would have helped immensely to better understand the connection between realworld data and artistic interpretation. This software was created with the intent that graphical scores could be projected for audiences so a deeper understanding of cause and effect could be achieved. It was difficult to ascertain an internal logic while listening to the piece and seeing the abstracted data. Maybe an overlay of the original sketches by the archaeologists or pictures of the dig itself might have deepened the audience's reaction to the piece.

The double bass is an interesting instrument, in part because the high registers (including harmonics) can be used in such powerful and interesting ways in combination with the low end and the huge resonating body. The melodic line of Yabaney Inlet, for double bass and electronics by McGregor Boyle was inspired by plainchant and heavily quotes the hymn "Veni Creator Spiritus". This moves to piece into a modal plane, which was underscored by the use of prerecorded sounds from Yahaney Inlet. The bass was simply processed, it seemed with delay and feedback to prolong certain notes. Indeed, the program note confirmed that pitch tracking was used to sustain certain notes. However, the integration of the live processing with the pre-recorded material was not convincing. The tessitura for the melody also seemed awkward for the double bass and might have been better suited for the cello. The low range of the bass was never explored, nor the extreme high register, where more timbrally interesting material might have emerged.

Han:geul was a piece for janggu and motion graphic score by Deborah Kim. "Han:geul", as the composer informed the audience in a pre-performance introduction, entitles the Korean alphabet. The audience should be able to learn and better understand Korean traditional janggu drumming by the end of the piece via a motion graphic score. This visual score, which was invented by the composer, used traditional janggu 
notation along with images and video that the performer had to interpret.

The concept of the motion graphic score is intriguing, however the claims that it is a "communicational device that is first interpreted by the performer, and then understood by the audience" with the "cultural and historical dimension of the creation of Hangeul, and its aesthetics variety and complexity $[. .$.$] embedded in$ the visual component of the work" are lofty goals. These goals were not entirely met, as the visual component did little to educate an uninformed audience about Han:geul or janggu performance.

Initially I was disappointed by Ecosystemic Improvisation System no. 3 for live electronics by Michael Musick, because of the lack of formal cohesion, cliché sounds and DSP processes, especially as the idea of ecosystemic performance is one I am quite familiar with. The title conjured memories of the work of Agostino $\mathrm{Di}$ Scipio, which sets a type of expectation for listeners familiar with this research and work. "Ecosystemic", "improvisation", and "system" are very semantically charged words, which also influenced or pre-set expectations. In hindsight, however, the piece is much more effective, after some distance to the performance and having now read the program notes. Here it is crucial to know about the independent agents in the system and their relationships and interactions, which now explains the somewhat rough edges concerning form or sonic cohesion of materials. Knowing of the intended interactions, or non-interactions, shifts the focus away from overall formal structure, even the sounds themselves, and invites the listener to participate in an adventure where sounds and parameters are shared between independent/interdependent players to create an altogether unexpected whole.

Barry Truax, one of the keynote speakers, performed two pieces in this concert. Truax is known, among other things for his contributions in Acoustic Ecology, continuing the work of R. M. Schafer, and his work on granular synthesis and his PODX system. His two pieces "Earth and Steel" and "The Garden of Sonic Delights" were easily the most polished and well-crafted contributions of the evening (if not the entire festival).

Earth and Steel, acousmatic work by Barry Truax conjured up images of a large, sonorous space where large metal objects were hit by other large metal objects. The 
program notes confirmed that the piece was an homage to the days "when large steel ships were built in enclosed slips". While the piece was extremely polished, had clean sound sources, and was expertly performed by Truax at the mixing desk (dancing along with the sounds, anticipating and reacting to the clangs at times), it still left me wanting. The promised "larger than life sounds" did not seem to appear at quite the imagined scale. The various hits of metal became predictable in their rhythmic, formal, and spatial treatment and their timbre remained virtually unchanged throughout, which is to be expected due to the conceptual framework Truax is working in. This is not to say that the piece was not enjoyable or boring to listen to, quite the opposite. Originally, this piece was performed in an enclosed metal slip, and I imagine that with the physically impressive spatial dimensions in combination with the unique acoustic environment, this piece surely must have lived up to the "larger than life sounds".

The Garden of Sonic Delights, acousmatic work by Barry Truax was a delightful walk through an imaginary garden. Much of it seems to have been inspired by the work of the World Soundscape Project and the soundscape/soundwalk compositions of Hildegard Westerkamp. The piece took the listener on a stroll during different times of the day and invoked sounds, although weirdly alien of water, wind, walking on foliage, etc. The stroll was pleasant, remarkable at times and all sounds seemed natural (even in their alienness) within the universe Truax created for the listener. However, like many other pieces, the solemn ambience at the end of Truax's piece was immediately broken by the audible sounds of the headsets of the crew, a technical error that should be avoided in the future. The one minor objection I might have is that the piece abandoned the alien soundscape at the end where a coda like section was now, presumable presenting us with the unaltered natural sounds used in the composition. While I can easily justify this compositional decision on various levels both technical and conceptual, for myself I would have like to remain in the garden Truax so painstakingly constructed for us in the course of this work. I did not need reality to intrude on my daydreams...

The scream for dance and audiovisual work by Byung Ki Kim was the last piece of the evening. It was an extravaganza of a live dance performance, audio, and video. 
It was the most ambitious work combining three different artistic practices at very high levels. Each component was well executed, had an internal flow and logic, and a formal trajectory. However, combining the three seemed to take away from each component as it became very difficult to connect the different practices into a whole narrative. Specifically, the two visual components, video projection and dance, seemed to be disconnected. This odd counterpoint may have been interesting to explore, however the music did not underscore this relationship or play with it but rather had its own trajectory. Each of the three components in combination with one of the others would make for a fascinating experience. Combining them, it unfortunately did not live up to what it could and should have been, given the quality of the components.

\section{Concert 9}

Wednesday, Aug. 8, 2018 10:30 a.m. Chamber Hall, Daegu Concert House Reviewed by Brian Questa

How can a composer approach recorded or found material? How much does the recording process itself effect our perception of the sound source? And where is the border between self- expression and a pure presentation? These questions were focal points in this concert, as each piece presented them in an interesting light.

Siting Jiang's To come into focus for snare drum and electronics was unique in a program of mostly fixed media works. Nevertheless, the piece still displayed a wide range of interactions possible between a sound source and its live processing. From the sonically distant yet strongly correlated, to the battling of the drum and electronics for the same acoustical space, the music, as it moved through the diverse interrelationships, presented a clear and emerging form, which aptly encased the work's engaging adaptation of more characteristic snare drum gestures.

Antonio D'Amato's Paysage marin avec bateaux et bydravion for fixed media did not shy from the fact that our perceptions of recorded environments are strongly influenced by the imposition of the recording process itself. His work highlighted this fact by introducing his own synthesized sounds, blending the electronic and environmental sources in a skillful spatialisation and composition. Instead of characteristically attempting to 